\title{
The chlamydial periplasmic stress response serine protease cHtrA is secreted into host cell cytosol
}

\author{
Xiang Wu, Lei Lei, Siqi Gong, Ding Chen, Rhonda Flores and Guangming Zhong*
}

\begin{abstract}
Background: The periplasmic High Temperature Requirement protein A ( $H$ trA) plays important roles in bacterial protein folding and stress responses. However, the role of chlamydial HtrA ( $\mathrm{cHtrA})$ in chlamydial pathogenesis is not clear.

Results: The cHtrA was detected both inside and outside the chlamydial inclusions. The detection was specific since both polyclonal and monoclonal anti-cHtrA antibodies revealed similar intracellular labeling patterns that were only removed by absorption with cHtrA but not control fusion proteins. In a Western blot assay, the anticHtrA antibodies detected the endogenous CHtrA in Chlamydia-infected cells without cross-reacting with any other chlamydial or host cell antigens. Fractionation of the infected cells revealed cHtrA in the host cell cytosol fraction. The periplasmic cHtrA protein appeared to be actively secreted into host cell cytosol since no other chlamydial periplasmic proteins were detected in the host cell cytoplasm. Most chlamydial species secreted cHtrA into host cell cytosol and the secretion was not inhibitable by a type III secretion inhibitor.

Conclusion: Since it is hypothesized that chlamydial organisms possess a proteolysis strategy to manipulate host cell signaling pathways, secretion of the serine protease cHtrA into host cell cytosol suggests that the periplasmic cHtrA may also play an important role in chlamydial interactions with host cells.
\end{abstract}

Keywords: Chlamydia trachomatis $\mathrm{CHtrA}$, serine protease, secreted protein

\section{Background}

The genus Chlamydia consists of multiple obligate intracellular bacterial species that infect both humans and animals. The C. trachomatis organisms infect human ocular (serovars A to C) and urogenital/colorectal (serovars D to K \& L1 to L3) epithelial tissues, causing trachoma [1] and sexually transmitted diseases [2-4] respectively; The $C$. pneumoniae organisms invade human respiratory system, not only causing respiratory diseases but also exacerbating pathologies in cardiovascular system [5-7]; C. muridarum (formerly known as C. trachomatis mouse pneumonitis agent, designated as MoPn; ref: [8]), although causing no known diseases in humans, has been used as a model pathogen for studying chlamydial pathogenesis and immune responses; The $C$. psittaci $6 \mathrm{BC}$ organisms that naturally infect birds can cause severe pneumonia in humans [9] while the C. caviae GPIC organisms can infect ocular and urogenital tissues in guinea pig [10]. Despite the

\footnotetext{
* Correspondence: Zhongg@UTHSCSA.edu

Department of Microbiology and Immunology, University of Texas Health Science Center at San Antonio, 7703 Floyd Curl Drive, San Antonio, TX 78229, USA
}

differences in host range, tissue tropism, disease processes, all chlamydial species share similar genome sequences $[8,10,11]$ and possess a common intracellular growth cycle with distinct biphasic stages [12]. A chlamydial infection starts with the invasion of an epithelial cell by an infectious elementary body (EB). The internalized EB rapidly develops into a noninfectious but metabolically active reticulate body (RB) that undergoes multiplication. The progeny RBs then differentiate back into EBs for spreading to new cells. All chlamydial biosynthesis activities are restricted within a cytoplasmic vacuole known as inclusion [12].

During the intravacoular developmental cycle, chlamydial organisms have to take up nutrients and energy from host cells [13-16] and maintain the integrity of the host cells [17]. To achieve these goals, chlamydial organisms have evolved the ability to secrete proteins into the inclusion membrane $[18,19]$ and host cell cytoplasm $[17,20,21]$. Identifying the chlamydial secretion proteins has greatly facilitated the understanding of chlamydial pathogenic mechanisms [20,22-31]. CPAF, a chlamydial protease/ proteasome-like activity factor that is now known as a serine protease [32,33], was found to secrete into host cell

\section{Biomed Central}


cytosol more than a decade ago [26]. CPAF can degrade a wide array of host proteins including cytokeratins for facilitating chlamydial inclusion expansion [34-36], transcriptional factors required for $\mathrm{MHC}$ antigen expression for evading immune detection $[37,38]$ and $\mathrm{BH} 3$-only domain proteins for blocking apoptosis $[39,40]$. Another example of chlamydia-secreted proteins is the chlamydial tail-specific protease that has been found to dampen the inflammatory responses by cleaving host NF- $\kappa \mathrm{B}$ molecules $[41,42]$. These observations have led to the hypothesis that Chlamydia may have evolved a proteolysis strategy for manipulating host cell signaling pathways [17].

Among the several dozens of putative proteases encoded by chlamydial genomes $[11,43]$, the chlamydial HtrA (cHtrA) is a most conserved protease. HtrA from eukaryotic and prokaryotic species exhibits both chaperone and proteolytic activities $[44,45]$ with a broad proteolytic substrate specificity $[44,45]$. HtrA is a hexamer formed by staggered association of trimeric rings and access to the proteolytic sites in central cavity is controlled by $12 \mathrm{PDZ}$ domains in the sidewall $[46,47]$. In eukaryotic cells, HtrA responds to unfolded proteins in the endoplasmic reticulum (ER) by cleaving and releasing the ER membraneanchored transcription factors ATF6 and SREBP into nucleus to activate the expression of proteins required for the unfolded protein response and cholesterol biosynthesis $[48,49]$. In bacteria, the periplasmic HtrA, in response to the binding of C-terminal peptides from unfolded/reduced outer membrane proteins, cleaves and releases the $\sigma^{\mathrm{E}}$-factor to activate stress response genes [50]. Since HtrA is required for bacterial survival under high temperature, it is called High Temperature Requirement (Htr) protein [51]. Although both the tertiary structure and the function of HtrA are well known, the role of cHtrA in chlamydial pathogenesis remains unclear. In the current study, we have localized cHtrA both in the chlamydial inclusions and the host cell cytosol. The specificity of the antibody labeling and cytosolic localization of cHtrA were confirmed in independent assays. The secretion of the periplasmic cHtrA into host cell cytosol appeared to be an active/selective process since no other chlamydial periplasmic proteins were detected outside the chlamydial inclusions. Thus, the chlamydial periplasmic cHtrA may also contribute to the chlamydial proteolysis strategies for manipulating host cell signaling pathways.

\section{Methods}

\section{Chlamydial infection}

The following chlamydial organisms were used in the current study: C. trachomatis serovars A/HAR-13, B/HAR-36, $\mathrm{Ba} / \mathrm{Ap}-2$, C/UW-1, D/UW-3/Cx, E/UW-5/CX), F/IC-Cal3, H/UW-43/Cx, I/UW-12/Ur, K/UW-31/Cx, L1/LGV440, L2/LGV-434/Bu \& L3/LGV-404, C. muridarum (Nigg), C. pneumoniae (AR39), C. caviae (GPIC) \&
C. psittaci (6BC). All chlamydial organisms were either purchased from ATCC (Manassas, VA) or acquired from Dr. Harlan Caldwell at the Rocky Mountain Laboratory, NIAID/NIH (Hamilton, MT) or Dr. Ted Kou at the University of Washington (Seattle, WA). The chlamydial organisms were propagated, purified, aliquoted and stored as described previously [26]. All chlamydial organisms were routinely checked for mycoplasma contamination. For infection, HeLa cells (human cervical carcinoma epithelial cells, ATCC cat\# CCL2) grown in either 24 well plates with coverslips or tissue flasks containing DMEM (GIBCO BRL, Rockville, MD) with 10\% fetal calf serum (FCS; GIBCO BRL) at $37^{\circ} \mathrm{C}$ in an incubator supplied with $5 \% \mathrm{CO} 2$ were inoculated with chlamydial organisms. The infected cultures were processed at various time points after infection for either immunofluorescence assays or Western blot analysis as described below. In some experiments, at 6 hours after infection, the cultures were treated with a C1 compound [N'-(3,5-dibromo-2-hydroxybenzylidene)-4-nitrobenzohydrazide, cat\#5113023, ChemBridge, San Diego, CA], a small molecule known to inhibit Yersinia type III secretion system (T3SS) and block chlamydial growth [52]. The treated cultures were processed for immunofluorescence microscopy analysis at 36 hours after infection. The $\mathrm{C} 1$ compound was dissolved in dimethyl sulfoxide (DMSO; Sigma, St Luis, MO) at a stock concentration of $50 \mathrm{mM}$ and diluted into culture medium at a final concentration of $50 \mu \mathrm{M}$ with $0.1 \%$ DMSO.

\section{Chlamydial gene cloning, fusion protein expression and antibody production}

The ORF CT823 (cHtrA) from C. trachomatis serovar D organisms was cloned into pGEX vectors (Amersham Pharmacia Biotech, Inc., Piscataway, NJ). The following primers were used for cloning the ORF: cHtrA forward primer, 5'-CGC-GGATCC (BamHI)-ATGATGAAAAGAT TATTATGTGTG-3', cHtrA back primer, 5'-TTTT CCTTTT-GCGGCCGC(NotI)-CTACTCGTCTGATTTCAAGAC-3'. The ORF was expressed as a fusion protein with glutathione-S-transferase (GST) fused to the Nterminus as previously described [53]. Expression of the fusion protein was induced with isopropyl-beta-D-thiogalactoside (IPTG; Invitrogen, Carlsbad, CA) and the fusion proteins were extracted by lysing the bacteria via sonication in a Triton-X100 lysis buffer (1\%TritonX-100, $1 \mathrm{mM}$ PMSF, 75 units/ml of Aprotinin, $20 \mu \mathrm{M}$ Leupeptin and 1.6 $\mu \mathrm{M}$ Pepstatin, all from Sigma). After a high-speed centrifugation to remove debris, the fusion protein was purified using glutathione-conjugated agarose beads (Pharmacia) and the purified protein was used to immunize mice for producing antibodies, including monoclonal antibodies (mAbs), as described previously [53-55]. The mouse antibodies against GST-CT067, GST-CT539 and GST-CT783 were produced similarly. The fusion protein-specific 
antibodies were used to localize endogenous proteins in C. trachomatis-infected cells via an indirect immunofluorescence assay and to detect endogenous proteins using a Western blot assay. All mouse anti-GST fusion protein antibodies were preabsorbed with bacterial lysates containing GST alone before any applications. In some experiments, the GST fusion proteins bound onto the glutathione-agarose beads were also used to absorb the mouse antibodies to confirm antibody specificities.

\section{Immunofluorescence assay}

The immunofluorescence assay was carried out as described previously [55]. Briefly, HeLa cells grown on coverslips were fixed with $2 \%$ paraformaldehyde (Sigma, St. Luis, MO) for $30 \mathrm{~min}$ at room temperature, followed by permeabilization with $2 \%$ saponin (Sigma) for an additional $30 \mathrm{~min}$. After washing and blocking, the cell samples were subjected to antibody and chemical staining. Hoechst (blue, Sigma) was used to visualize DNA. A rabbit anti-chlamydial organism antibody (R1L2, raised with C. trachomatis L2 organisms, unpublished data) or antiIncA from C. trachomatis [kindly provided by Ted Hackstadt. Laboratory of Intracellular Parasites, Rocky Mountain Laboratories, NIAID, NIH, Hamilton, Montana; [56]], C. pneumoniae or C. psittaci (both current study) plus a goat anti-rabbit IgG secondary antibody conjugated with Cy2 (green; Jackson ImmunoResearch Laboratories, Inc., West Grove, PA) was used to visualize chlamydial organisms or inclusion membrane. The various mouse antibodies plus a goat anti-mouse IgG conjugated with $\mathrm{Cy} 3$ (red; Jackson ImmunoResearch, West Grove, PA) were used to visualize the corresponding antigens. The mouse antibodies used included: polyclonal antibodies (pAbs) made against GST-CT823 (HtrA), GST-CT783, GST-CT621, GST-CT539, GST-CT067 (all current study) and mAbs 6A2 against HtrA (current study), 100a against CPAF [26], BB2 against IncA (CT119) \& 1L11C3 against chlamydial HSP60 (unpublished data). All primary antibodies were preabsorbed with a bacterial lysate containing GST alone before use. In addition, for some experiments, the primary antibodies were absorbed with either the corresponding or heterologous fusion proteins immobilized onto glutathioneconjugated agarose beads (Pharmacia). The absorption was carried out by incubating the antibodies with beadimmobilized antigens for $1 \mathrm{~h}$ at room temperature (RT) or overnight at $4^{\circ} \mathrm{C}$ followed by pelleting the beads. The remaining supernatants were used for immunostaining. The immunofluorescence images were acquired using an Olympus AX-70 fluorescence microscope equipped with multiple filter sets and Simple PCI imaging software (Olympus, Melville, NY) as described previously [40]. An Olympus FluoView laser confocal microscope (Olympus, Center Valley, PA) was used to further analyze some of the immunofluorescence samples at the University of Texas Health Science Center at San Antonio institutional core facility as described previously [29]. The images were processed using Adobe Photoshop (Adobe Systems, San Jose, CA).

\section{Western blot assay}

The Western blot assay was carried out as described elsewhere $[38,55]$. Briefly, HeLa cells with or without C. trachomatis infection and with or without fractionation (into pellet and S100 fractions), purified chlamydial RB and EB organisms, GST fusion proteins or fractionated bacterial periplasmic or cytosolic samples were resolved in SDS polyacrylamide gels. The resolved protein bands were transferred to nitrocellulose membranes for antibody detection. The primary antibodies used included: mouse $\mathrm{pAb}$ and mAb 6A2 against cHtrA, mouse pAb against CT067 (all current study), mAb 100a against CPAF [26], mAb MC22 against chlamydial major outer membrane protein [MOMP; ref [26]], mAb W27 against host cell HSP70 (cat\#Sc-24, Santa Cruz Biotechnology, CA), mAb against FLAG tag (cat\#F3165, Sigma, St. Luis, MO) and rabbit polyclonal antibody against bacterial GroEL (cat\#G6532, Sigma, St. Luis, MO). The anti-MOMP antibody was used to ensure that all lanes with chlamydial organism-containing samples were loaded with equivalent amounts of the organisms while the lanes without chlamydial organism samples should be negative for MOMP. The anti-HSP70 antibody was used to make sure that equal amounts of normal HeLa and Chlamydia-infected HeLa samples were loaded and to also check whether the cytosolic fractions are contaminated with components from the pellet fractions during cellular fractionation (see below). All primary antibodies used in the current study were pre-absorbed with an excess amount of bacterial lysates containing the GST alone. The primary antibody binding was probed with an HRP (horse radish peroxidase)-conjugated goat anti-mouse IgG secondary antibody (Jackson ImmunoResearch, West Grove, PA) and visualized with an enhanced chemiluminescence (ECL) kit (Santa Cruz Biotech). Some of the C. trachomatis-infected HeLa cell (Ct-HeLa) samples were fractionated into pellet (containing host cell nuclei and chlamydial inclusions) and cytosolic fraction (S100, containing Chlamydia-secreted proteins) as described previously [26,29]. Briefly, cell samples were collected by centrifugation at $600 \mathrm{~g}$ for $10 \mathrm{~min}$ at $4{ }^{\circ} \mathrm{C}$. The cell pellets were washed once with ice-cold PBS and resuspended with five volumes of buffer A (20 $\mathrm{mM}$ Hepes-KOH, pH 7.5, $10 \mathrm{mM} \mathrm{KCl,} 1.5 \mathrm{mM} \mathrm{MgCl}_{2}$, $1 \mathrm{mM}$ sodium EDTA, $1 \mathrm{mM}$ sodium EGTA, $1 \mathrm{mM}$ dithiothreitol, and $0.1 \mathrm{mM}$ phenylmethylsulfoyl fluoride) containing $250 \mathrm{mM}$ sucrose on ice for $15 \mathrm{~min}$. The cells were homogenized with 10 to 15 strokes using a number 22 kontes douncer with the B pestle (Kontes Glass Company, 
Vineland, NJ) to break cytoplasmic membrane but without breaking inclusion/nuclear membrane. The integrity of cytoplasmic and inclusion/nuclear membranes was monitored microscopically by smearing an aliquot of the homogenates on a slide. The final homogenates were centrifuged twice at $750 \mathrm{~g}$ for $10 \mathrm{~min}$ at $4^{\circ} \mathrm{C}$ to pellet inclusions/nuclei. The pellets from both centrifugations were combined and washed once with cold PBS and stored as pellet fraction. The supernatants were centrifuged at $10,000 \mathrm{~g}$ for $15 \mathrm{~min}$ at $4^{\circ} \mathrm{C}$ followed by a further centrifugation at $100,000 \mathrm{~g}$ for $1 \mathrm{~h}$ at $4^{\circ} \mathrm{C}$. The resulting supernatants were designated as S100 or cytosolic fraction. The chlamydial organisms were purified as described previously [43]. The RB organisms were purified from $24 \mathrm{~h}$ cultures while the EB organisms from 40 to $50 \mathrm{~h}$ cultures. The bacterial cell fraction samples were prepared as the following: a pellet from $10 \mathrm{ml}$ bacteria culture was washed with ice-cold PBS once and pelleted again by centrifugation at $3000 \mathrm{rmp} \times 10 \mathrm{~min}$ at $4^{\circ} \mathrm{C}$. The pelleted bacterial cells were resuspended in $0.5 \mathrm{ml}$ of a Periplasting buffer containing $20 \mathrm{mM}$ Tris- $\mathrm{HCl}$ (pH7.5), 20\% sucrose (cat\#SX1075-1, EMD Chemicals Inc., Gibbstown, NJ), $1 \mathrm{mM}$ EDTA (cat\#E5134, Sigma), $3 \mathrm{mg} / \mathrm{ml}$ lysozyme (cat\#100834, MP biomedicals, Solon, Ohio). After incubating on ice for $5 \mathrm{~min}, 0.5 \mathrm{ml}$ ice-cold distilled water was added to the suspension and mixed by pipetting up and down. After incubating on ice for another $5 \mathrm{~min}$, the mixture was pelleted by centrifugation at $12,000 \mathrm{~g}$ for $2 \mathrm{~min}$ at $4^{\circ} \mathrm{C}$. The periplasmic fraction (per) in the supernatant was collected to a new tube while the cytoplasmic proteins (cyt) in the remaining pellet were resuspended in $1 \mathrm{ml}$ Periplasting buffer. Both per \& cyt fractions were used on the Western blot assay.

\section{BCIP Assay}

To construct the plasmid pFLAG-CTC-cHtrAss-'PhoA, a 69 bp DNA sequence coding for the HtrA signal peptide (M1-S23, designated as cHtrAss, with restriction enzyme sites of Xhol/BamHI) was amplified from Chlamydia trachomatis serovar D genome and 1400 bp DNA sequence coding for 'PhoA (BamHI/KpnI) was amplified from pFLAG-CTC-CPAFss-'PhoA plasmid, both 69 bp HtrA and $1400 \mathrm{bp}$ 'PhoA were inserted into the $\mathrm{XhoI} / \mathrm{KpnI}$ sites of the plasmid pFLAG-CTC (cat\#E8408, sigma; 'PhoA stands for mature PhoA without the signal peptide). The DH5a bacterial strain (Invitrogen, Carlsbad, CA) was used to express the plasmids. The products from all the three plasmids (pFLAG-PhoA, pFLAG'PhoA \& pFLAG-HtrAss-'PhoA) contain a FLAG tag fused to the C-terminus of PhoA. For BCIP assay, bacterial cells were grown in LB supplemented with the corresponding selection antibiotics at $37^{\circ} \mathrm{C}$ overnight. The overnight cultures were streaked onto LB agar containing the same selection antibiotics and $50 \mu \mathrm{g} / \mathrm{ml} \mathrm{5-bromo-4-}$ chloro-3-indolyl phosphate (BCIP, cat\# B6149, Sigma) and the plates were incubated at $30^{\circ} \mathrm{C}$ for 2 days. The bacterial colonies that are capable of exporting mature PhoA into periplasm turn blue while the colonies incapable of doing so remain white.

\section{Results}

1. Chlamydial HtrA is localized in both chlamydial inclusion and host cell cytosol

A mouse antiserum raised with GST-cHtrA fusion protein detected the endogenous cHtrA protein both inside and outside of the chlamydial inclusions in C. trachomatisinfected HeLa cells (Figure 1A). The amount of intrainclusion labeling appeared to be greater since the labeling in the host cell cytosol (outside inclusions) disappeared first as the dilution of the antiserum increased. Interestingly, some of the cHtrA-positive intra-inclusion granules appeared to be distinct from C. trachomatis organisms, suggesting that a portion of cHtrA may be secreted out of the organisms but still trapped inside the inclusions. Both the intra-inclusion and cytosolic distribution of cHtrA were confirmed with a mAb against cHtrA (Figure 1B). Similar intra-inclusion stainings that are free of organisms were reported previously $[15,57,58]$. In contrast, most CPAF molecules were secreted out of the inclusions without obvious intra-inclusion accumulation. As expected, most of the chlamydial HSP60 molecules co-localized with the chlamydial organisms. The secretion of cHtrA into host cell cytosol became more obvious when the chlamydial inclusion membrane was counter-labeled using an anti-inclusion membrane protein antibody (Figure 1C). The cHtrA molecules were detected both inside and outside the inclusion membrane. The above observations together suggested that cHtrA might be secreted into both intra-inclusion space and the host cell cytosol.

We next confirmed the antibody binding specificity by using an absorption procedure (Figure 2A). Both the intrainclusion and host cell cytosolic signals detected by the anti-cHtrA antiserum or anti-cHtrA mAb $6 \mathrm{~A} 2$ were removed by absorption with GST-cHtrA but not GSTCPAF fusion proteins. Similarly, the cytosolic signal detected with the anti-CPAF antibody was removed by absorption with the GST-CPAF but not GST-cHtrA fusion proteins, demonstrating that the anti-cHtrA and anti-CPAF antibodies specifically labeled the corresponding endogenous proteins without cross-reacting with each other. In a Western blot assay (Figure 2B), the anti-cHtrA antibodies recognized both the GST-cHtrA fusion protein and the endogenous cHtrA from the $C$. trachomatis-infected HeLa cells (Ct-HeLa) while the various control antibodies recognized the corresponding antigens without any significant cross-reactivity with each other. The anti-CPAF antibody detected the GST-CPAF fusion protein and also the Cterminal fragment $(\mathrm{CPAF})$ of the endogenous $\mathrm{CPAF}$ from 

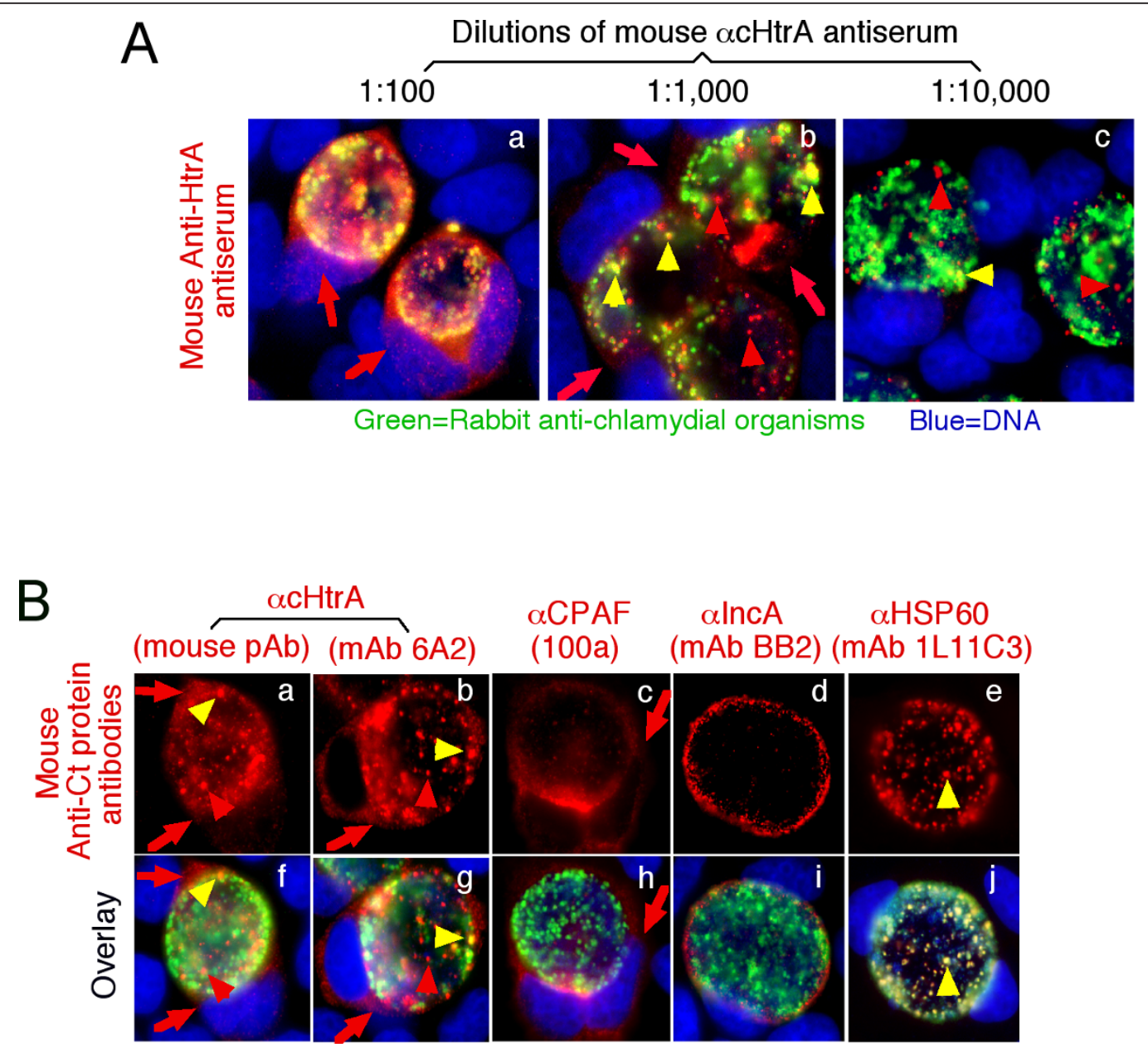

Green=Rabbit anti-chlamydial organisms Blue=DNA

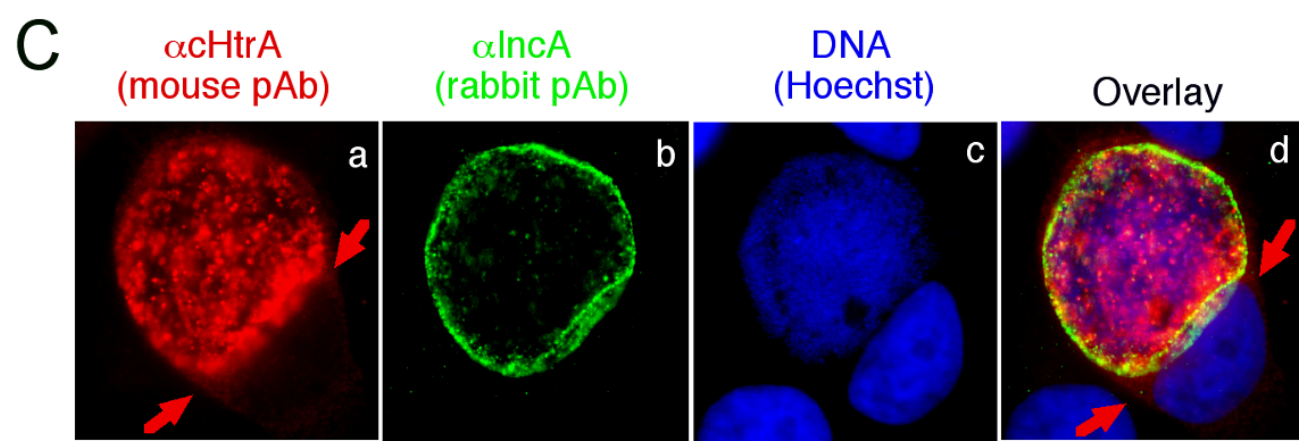

Figure 1 Detection of cHtrA protease in the cytosol of C. trachomatis-infected cells. HeLa cells infected with C. trachomatis L2 organisms were processed for co-staining with mouse antibodies visualized with a goat anti-mouse IgG conjugated with Cy3 (red), rabbit antibodies visualized with a Cy2-conjugated goat anti-rabbit lgG (green) and the DNA dye Hoechst (blue). The mouse antibodies included an anti-cHtrA (CT823) antiserum (raised with GST-cHtrA fusion protein) at various dilutions (A), the anti-cHtrA antiserum at 1:1000 dilution (B, panels a \& f), mAb 6A2 (b \& g, also raised with the GST-cHtrA fusion protein), mAb (100a) against CPAF (c \& h), mAb (BB2) against IncA (d \& i) and mAb (1L11C3) against HSP60 (e \& j). The mouse anti-cHtrA staining (red) was also co-labeled with a rabbit anti-IncA antibody (green; C). Note that the anti-cHtrA antibodies detected signals both inside the chlamydial inclusions with (yellow arrowheads) or without (red arrowheads) overlapping with the chlamydial organisms and in the host cell cytosol (red arrows) while the anti-CPAF antibody mainly detected signals in the host cell cytosol. 


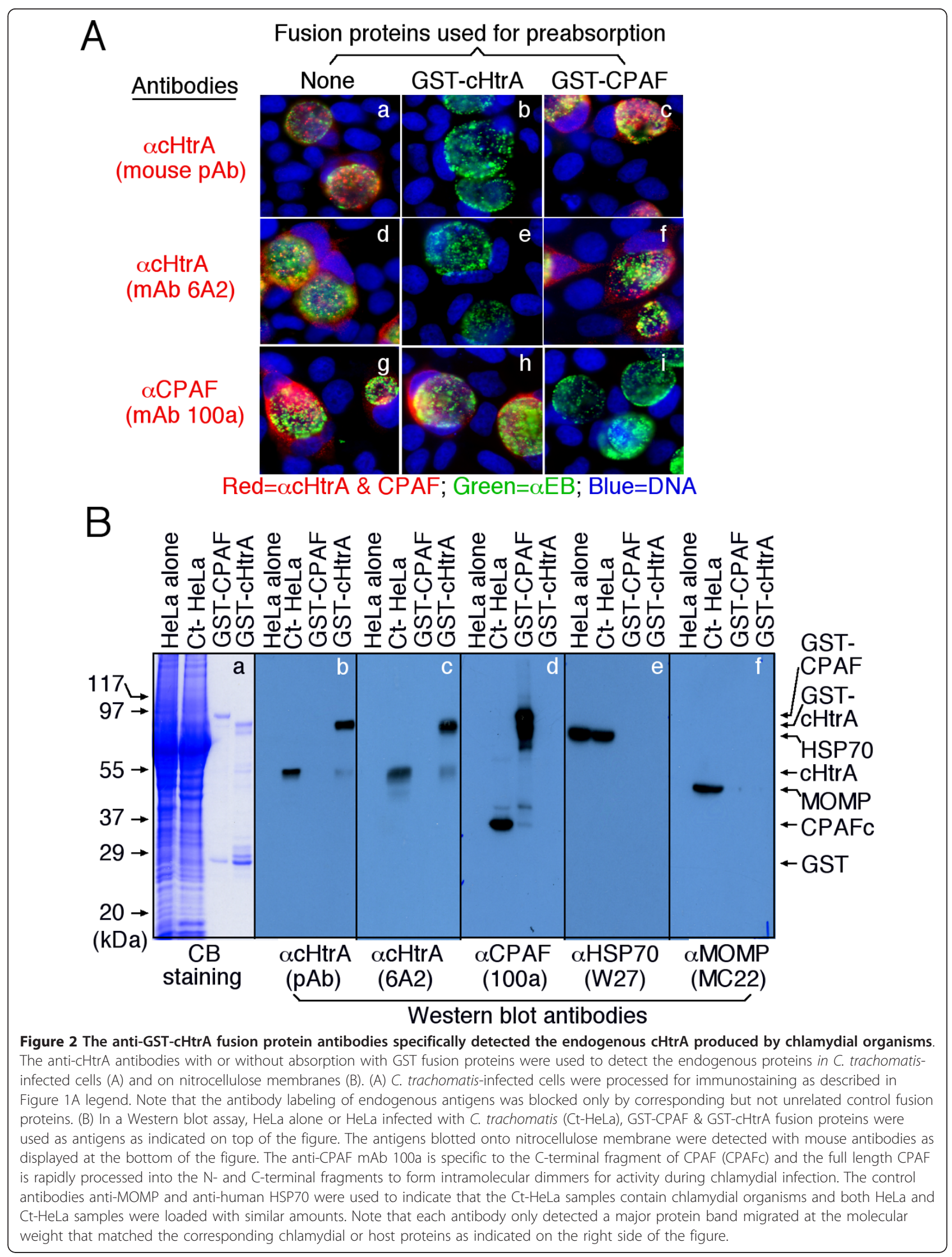


the Ct-HeLa sample. CPAF is rapidly processed into the $\mathrm{N}$ and $\mathrm{C}$-terminal fragments during chlamydial infection and the mAb 100a is specific to the $35 \mathrm{kDa}$ C-terminal fragment [26]. The anti-MOMP antibody detected MOMP from Ct$\mathrm{HeLa}$, confirming the presence of whole chlamydial organisms in the sample while the anti-human HSP70 antibody detected similar amounts of HSP70 in the HeLa alone and $\mathrm{Ct}$-HeLa samples, indicating that an equivalent amount of whole cell lysates was loaded in both samples. These observations together have demonstrated that the anti-cHtrA antibodies only recognized cHtrA without cross-reacting with any other chlamydial or host cell proteins, suggesting that the cellular signals detected with the anti-HtrA fusion protein antibodies in the immunofluorescence assay were specific to the endogenous cHtrA produced by chlamydial organisms.

\section{Secretion of cHtrA but not other chlamydial periplasmic proteins into host cell cytosol}

Since cHtrA is a periplasmic protein, we next tested whether localization in the host cell cytosol is a common characteristic of all chlamydial periplasmic proteins. The intracellular distributions of two periplasmic proteins involved in disulfide bond formation (CT539, TrxA or thioredoxin) and isomerization (CT783, PDI or protein disulfide bond isomerase; http://stdgen.northwestern.edu/) respectively and one periplasmic iron binding protein (CT067, YtgA, an ABC transporter system component; ref: $[59,60])$ were compared with that of cHtrA (Figure 3). Under a conventional fluorescence microscope (A), only cHtrA but not the other periplasmic proteins including CT067, CT539 \& CT783 was detected outside of the chlamydial inclusions. This observation was confirmed under a confocal microscope (B). The Z-axis serial section images showed that cHtrA was clearly detected both inside and outside the inclusion membrane but CT067 was only detected inside the inclusion membrane.

To directly visualize the molecular basis of the anticHtrA antibody-labeled cytosolic signals in Chlamydiainfected cells, the infected cells were fractionated into cytosolic (S100) and nuclear/inclusion (pellet) fractions. The distribution of cHtrA and CT067 in different fractions was compared in a Western blot (Figure 4). As a control for chlamydial proteins that are secreted into the host cell cytosol, CPAF was only detected in either the Chlamydiainfected whole cell lysate (Ct-HeLa) or cytosolic fraction (Ct-HeLa S100) samples but not other samples, which is consistent with what has been described previously [26]. Interestingly, cHtrA and its cleavage fragments but not CT067 was also detected in the cytosolic fraction, suggesting that cHtrA but not CT067 is secreted into host cell cytosol although both are periplasmic proteins. The cHtrA degradation fragments are likely generated during in vitro sample processing as HtrA is a powerful serine protease that is known to cleave itself [61]. To monitor the quality of the fractionation, the anti-MOMP antibody was used to indicate the pellet fraction that contains the chlamydial inclusions while an anti-human HSP70 antibody was used to indicate the host cell cytosolic fraction that contains the Chlamydia-secreted proteins. Detection with these antibodies revealed no cross contamination between the pellet and cytosolic fractions. In addition, detection with the anti-MOMP antibody also showed that the amounts of chlamydial organisms in the infected HeLa whole cell lysate, the pellet fraction and purified EB and RB samples were equivalent. These results together have independently confirmed that cHtrA is secreted into cytoplasm of Chlamydia-infected cells although it is also associated with the chlamydial RB and EB organisms.

\section{Expression and secretion of cHtrA during chlamydial infection}

We further used the specific anti-cHtrA antibodies to characterize the endogenous cHtrA. As shown in Figure 5, cHtrA protein was detected inside the inclusions as early as $12 \mathrm{~h}$ after infection and secretion of cHtrA into host cell cytosol became apparent by $24 \mathrm{~h}$ post infection. Although CPAF was also detectable at $12 \mathrm{~h}$, the secretion of CPAF was more robust and became very obvious as early as $16 \mathrm{~h}$ after infection. The cHtrA protein was detected both within the chlamydial inclusions and in the host cell cytosol while CPAF mainly accumulated in the host cell cytosol as infection progressed. Although both CPAF and cHtrA are serine proteases secreted by C. trachomatis organisms, their distinct secretion kinetics and intracellular distribution patterns suggest that they may fulfill different functions during chlamydial infection. To further evaluate whether cHtrA secretion is common to all chlamydial organisms, we monitored the cHtrA protein distribution in cells infected with various serovars and strains from different chlamydial species, including $13 \mathrm{C}$. trachomatis serovars and also isolates representing species of C. muridarum, C. caviae, C. pneumoniae and C. psittaci (Figure 6). The cHtrA protein was consistently detected in both the lumen of chlamydial inclusion and cytosol of host cells infected with all serovars of C. trachomatis organisms and isolates of C. muridarum, C. caviae and $C$. pneumoniae but not C. psittaci. Although secretion of cHtrA into the inclusion lumen and further into the cytosol of the infected cells seems to be a common feature of most chlamydial organisms tested, it is not known at this moment why the species $C$. psittaci, which primarily infect birds, failed to secrete cHtrA into host cytosol.

\section{The secretion of chlamydial HtrA may require a type II but not type III secretion pathway}

To determine the secretion pathway that chlamydial organisms may use to secrete cHtrA, we analyzed the 


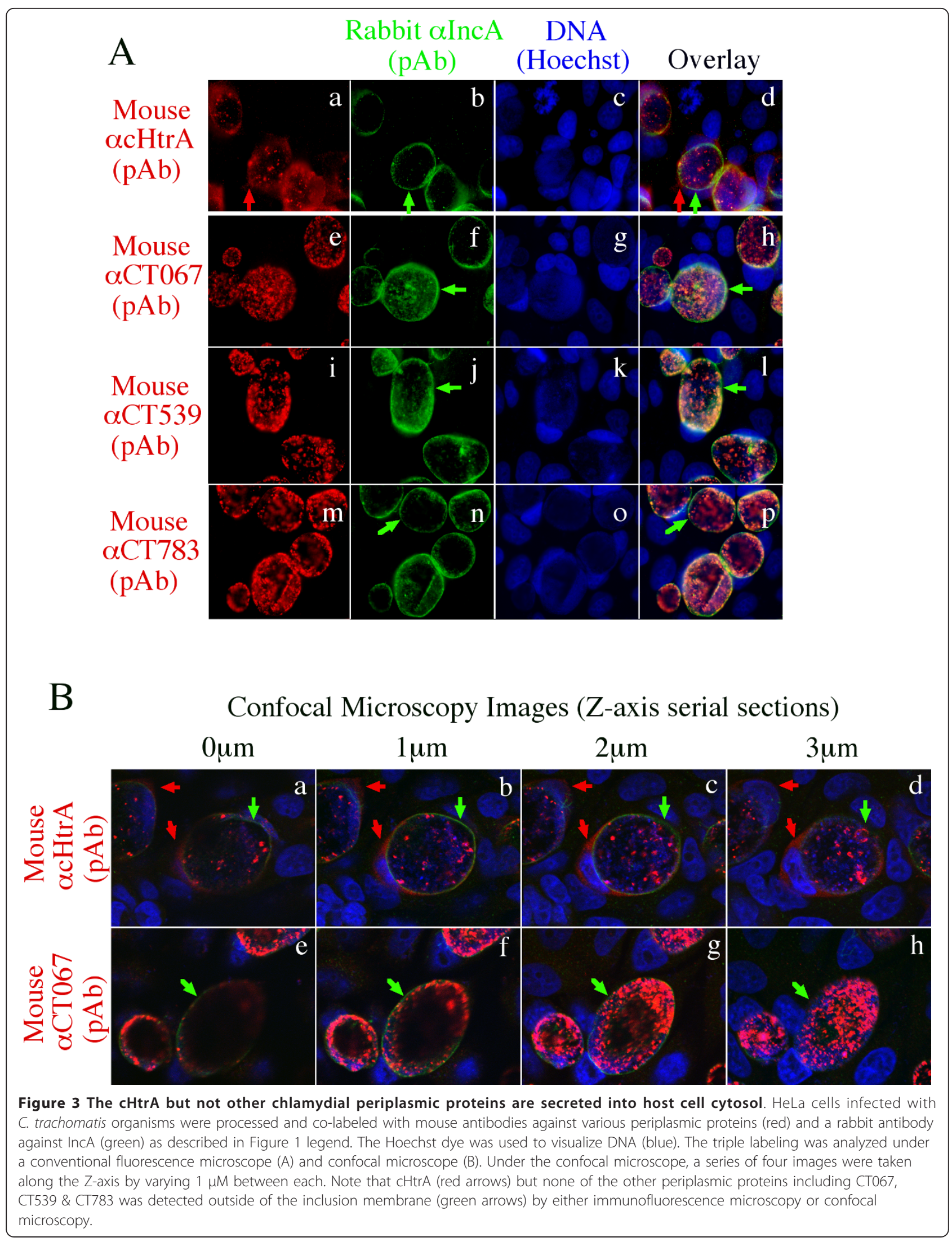



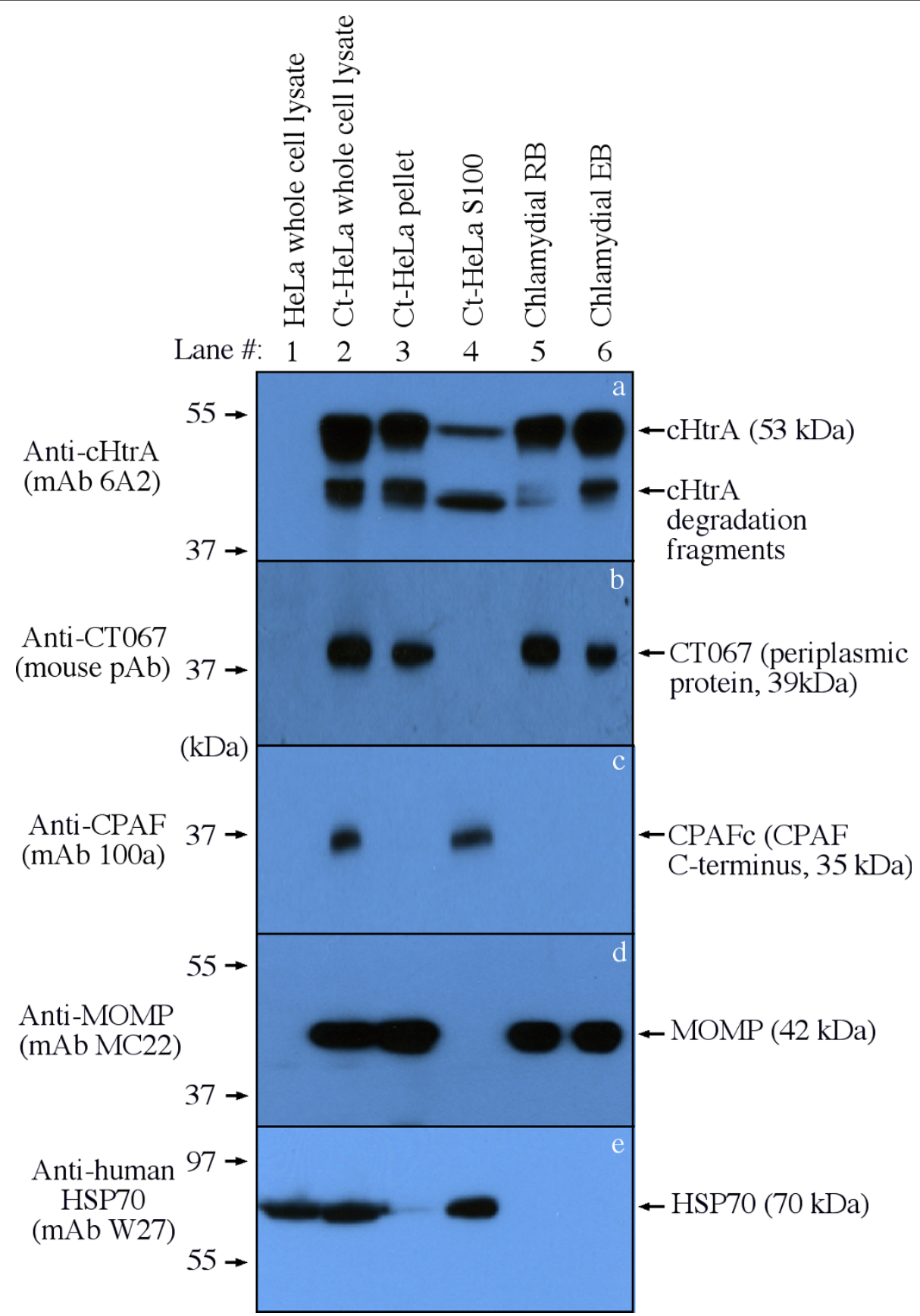

Figure 4 The cHtrA but not CT067 is detected in the cytosolic fraction of the chlamydia-infected HeLa cells. HeLa cells infected with C. trachomatis organisms (Ct-HeLa) were fractionated into nuclear (Ct-HeLa pellet, containing chlamydial inclusions, lane 3) and cytosolic (CtHeLa S100, containing chlamydia-secreted proteins, lane 4) fractions. The cellular fractions along with total cell lysates (normal HeLa, lane 1 \& CtHeLa, lane 2) and purified chlamydial RB (lane 5) and EB (lane 6) organisms as listed at the top were resolved in SDS-polyacrylamide gels. The resolved protein bands were blotted onto nitrocellulose membrane for reacting with antibodies (listed on the left) against cHtrA (panel a), CT067 ( $b$, a periplasmic iron binding protein), CPAF ( $c$, a chlamydia-secreted protein), MOMP ( $d$, a chlamydial outer membrane protein) and human HSP70 (e, a host cell cytosolic protein). All antibodies detected their corresponding proteins in the HeLa-L2 whole-cell lysate sample (lane 2) and other corresponding samples (as indicated on the right). Note that both cHtrA and CPAF but not CT067 or MOMP were detected in the cytosolic fraction (lane 4). CPAFc represents the C-terminal fragment of CPAF processed during chlamydial infection. The cHtrA degradation fragments (likely produced during in vitro sample processing) can always be detected with varying levels as HtrA is a powerful serine protease known to cleave itself [61] under certain conditions. 


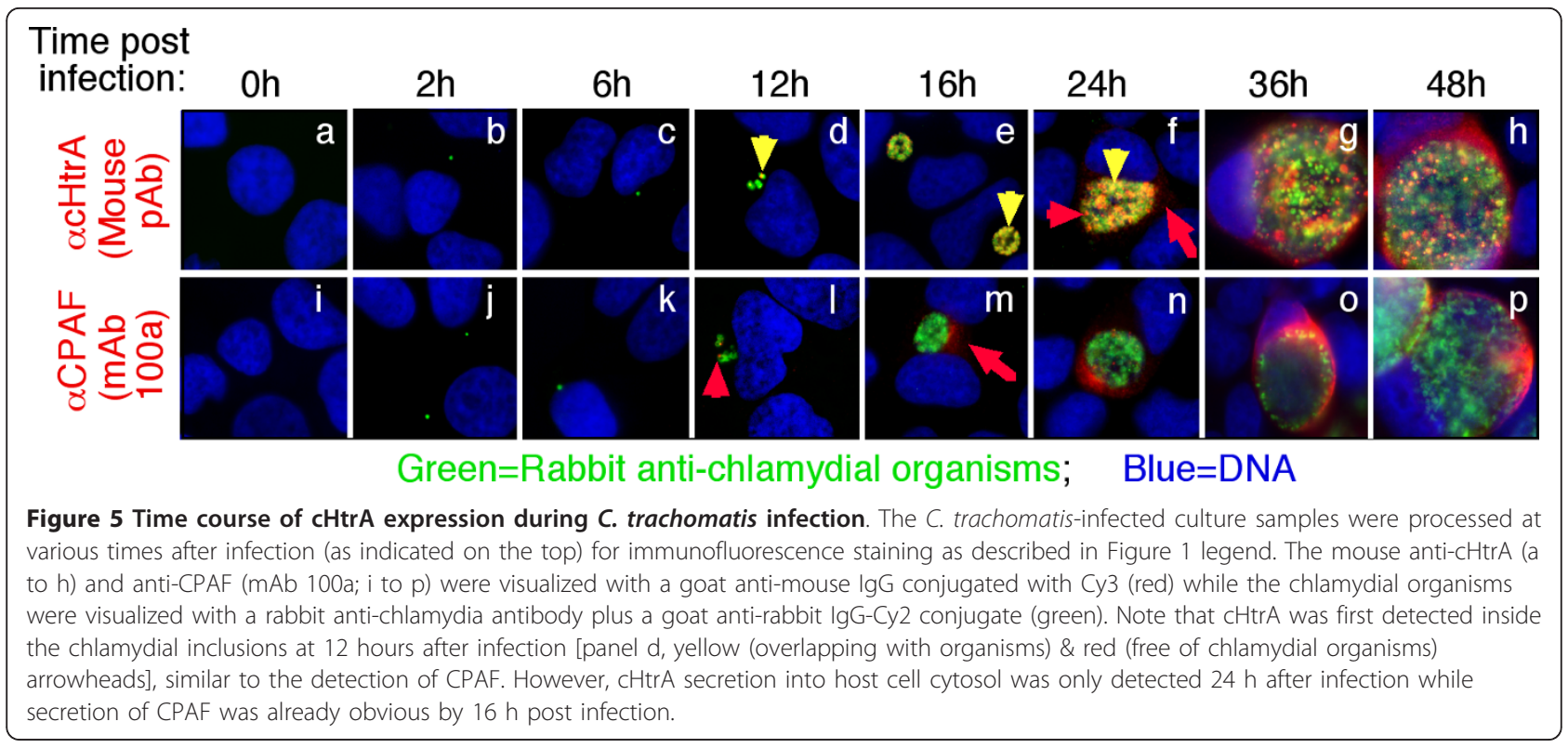

amino acid sequence of cHtrA for secretion signal sequences using the program SignalP version 3.0 with NN (neural network) and HMM (hidden markov model) algorithms http://www.expasy.ch. Both NN and HMM algorithms predict an $\mathrm{N}$-terminal signal peptide in cHtrA but with different cleavage sites. NN predicts a cleavage between S16 and S17 while HMM predicts the cleavage site between S23 and A24 (Figure 7A). We then tested the functionality of the $\mathrm{cHtrA} \mathrm{N}$-terminal sequence M1S23 using a bacterium-based phoA gene fusion system (Figure 7B \&7C). This assay system takes advantage of two characteristics of PhoA: the enzyme is only active after translocation into the bacterial periplasm, and the phosphatase activity can be conveniently monitored with the chromogenic substrate BCIP. DNA coding for the cHtrA N-terminal signal sequence covering residues M1 to S23 (designated as cHtrAss) was fused to the DNA sequence coding for mature PhoA (designated as 'PhoA). The fusion construct was expressed in pFLAG-CTC vector which adds a Flag epitope to the C-terminus of 'PhoA. The mature 'PhoA alone construct was used as a negative control while the precursor full-length PhoA (with its native $\mathrm{N}$-terminal signal peptide) served as a positive control. As shown in Figure 7B, in the presence of BCIP, bacteria expressing either the precursor PhoA or the cHtrAss-'PhoA fusion constructs turned blue whereas bacteria expressing the mature PhoA alone ('PhoA) remained white, indicating that both the native PhoA and cHtrA signal peptides directed the translocation of PhoA into periplasm. We further used a Western blot analysis to monitor the distribution of PhoA protein in periplasmic (per) and cytosolic (cyto) fractions (Figure 7C). Mature PhoA was detected in the periplasm of bacteria expressing either the precursor PhoA or HtrAss'PhoA fusion constructs while mature PhoA was only detected in the cytoplasm of the bacteria expressing the leaderless PhoA. Thus, the cHtrA N-terminal signal peptide is sufficient for directing PhoA across the bacterial inner membrane. We further found that the secretion of cHtrA was not inhibited by the $\mathrm{C} 1$ compound, an inhibitor known to inhibit chlamydial type III secretion system [52]. As positive controls, C1 inhibited the secretion of both IncA and CT621, two known chlamydial type III secretion substrates [30,52]. Consistently, the secretion of CPAF was not affected by $\mathrm{C} 1$. This is because secretion of CPAF is dependent on type II secretion pathway [62].

\section{Discussion}

The obligate intracellular growth of Chlamydia requires the organisms to intimately interact with host cells. Secretion of chlamydial proteins into host cells is necessary for chlamydial organisms to ensure a safe intracellular niche for completing biosynthesis and producing progenies. Identifying chlamydial proteins that are secreted into host cell cytoplasm has been a productive approach for understanding chlamydial pathogenic mechanisms [20,22-31]. In the current study, we characterized the chlamydial serine protease cHtrA by localizing its intracellular distribution. We have presented convincing evidence that $\mathrm{cHtr}$ A is secreted out of the chlamydial organisms into both chlamydial inclusion lumen and cytosol of the infected cells. First, both the cHtrA fusion protein-specific polyclonal and monoclonal antibodies detected intracellular secretion patterns distinct from those of CPAF, another secreted serine protease by chlamydial organisms. The cytosolic signals were confirmed using inclusion membrane as a 


\section{A}

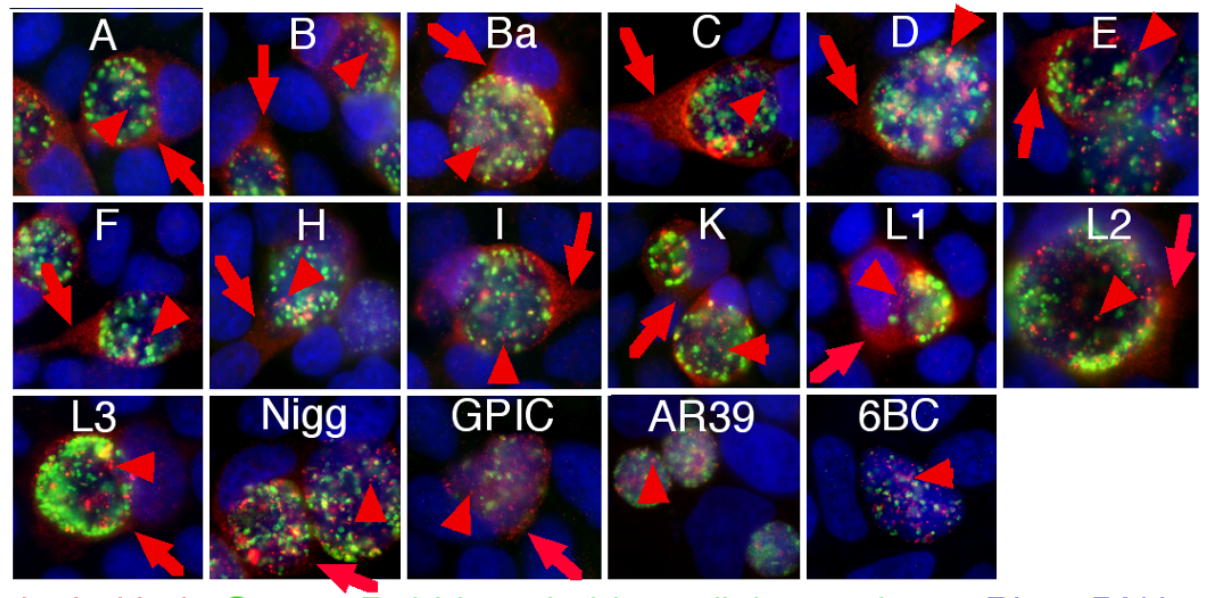

Anti-cHtrA; Green=Rabbit anti-chlamydial organisms; Blue=DNA

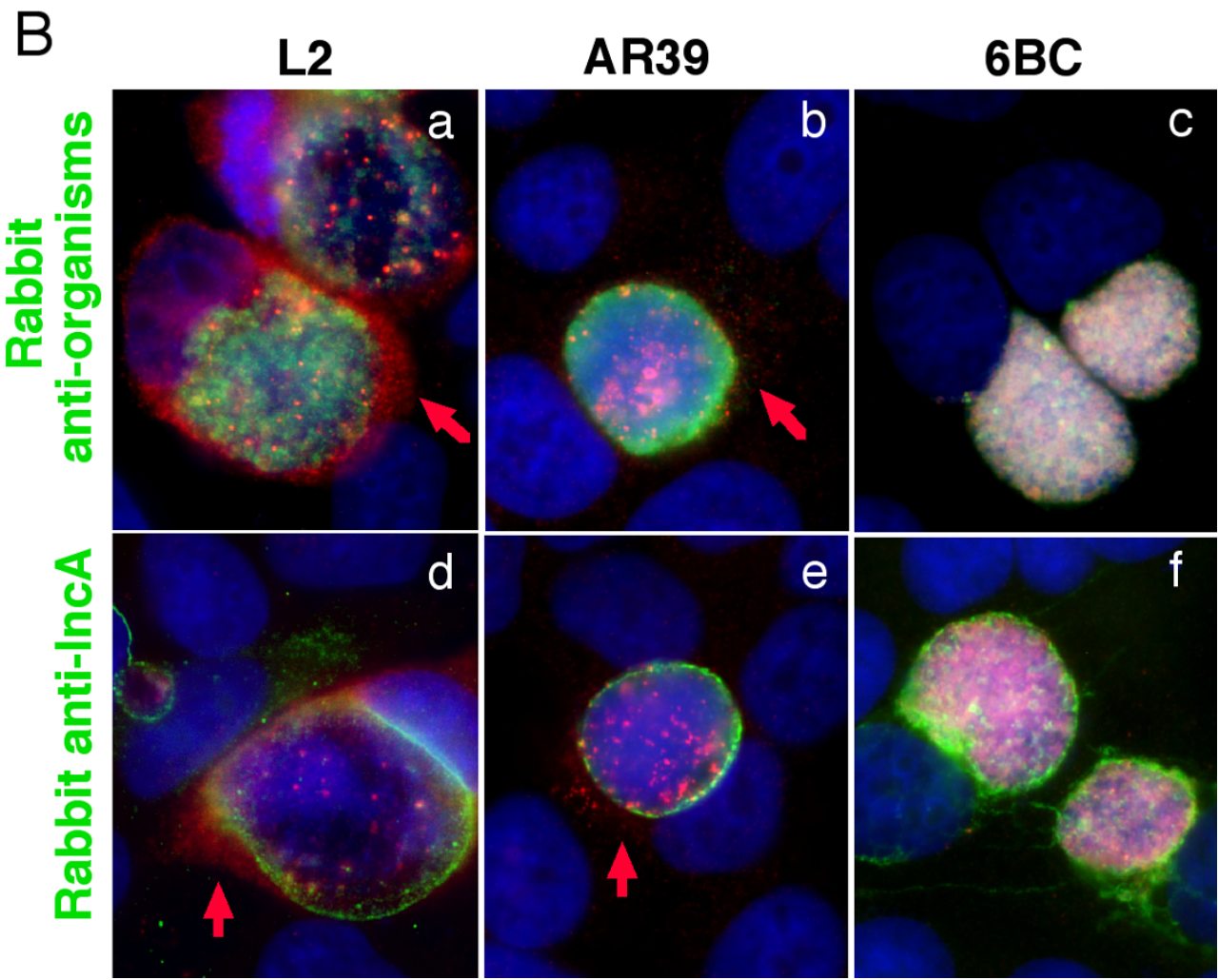

Figure 6 Secretion of cHtrA into host cell cytosol by most chlamydial organisms tested. HeLa cells infected with C. trachomatis serovars $A$, B, Ba, C, D, E, F, H, I, K, L1, L2, L3, C. muridarum Nigg strain, C. caviae GPIC, C. penumonaie AR39 isolate \&C. psiitaci 6BC organisms (as indicated in each panel) were processed at $40 \mathrm{~h}$ (all C. trachomatis serovars), $24 \mathrm{~h}$ (Nigg, GPIC \& 6BC) or $72 \mathrm{~h}$ (AR39) after infection. (A) The processed samples were detected for CHtrA using the mouse anti-cHtrA fusion protein polyclonal antibody (red) in an immunofluorescence assay. The chlamydial organisms were visualized using a rabbit anti-CT395 fusion protein antibody (green) while the DNA was labeled with Hoechst dye (blue). Note that cHtrA was consistently detected in both the lumen of chlamydial inclusion (red arrowheads) and cytosol (red arrows) of cells infected with all C. trachomatis serovars and C. muridarum and C. caviae isolates. However, the cytosolic labeling of cHtrA was not clear in cells infected with C. pneumoniae AR39 and C. psittaci 6BC organisms which were reexamined by co-staining with either anti-organisms (B, panels a-c) or anti-IncA (panels d-f) antibodies. Note that cytosolic cHtrA was detected in cells infected with C. pneumoniae AR39 (panels b \& e) but not C. psittaci 6BC organisms (c \& f). 


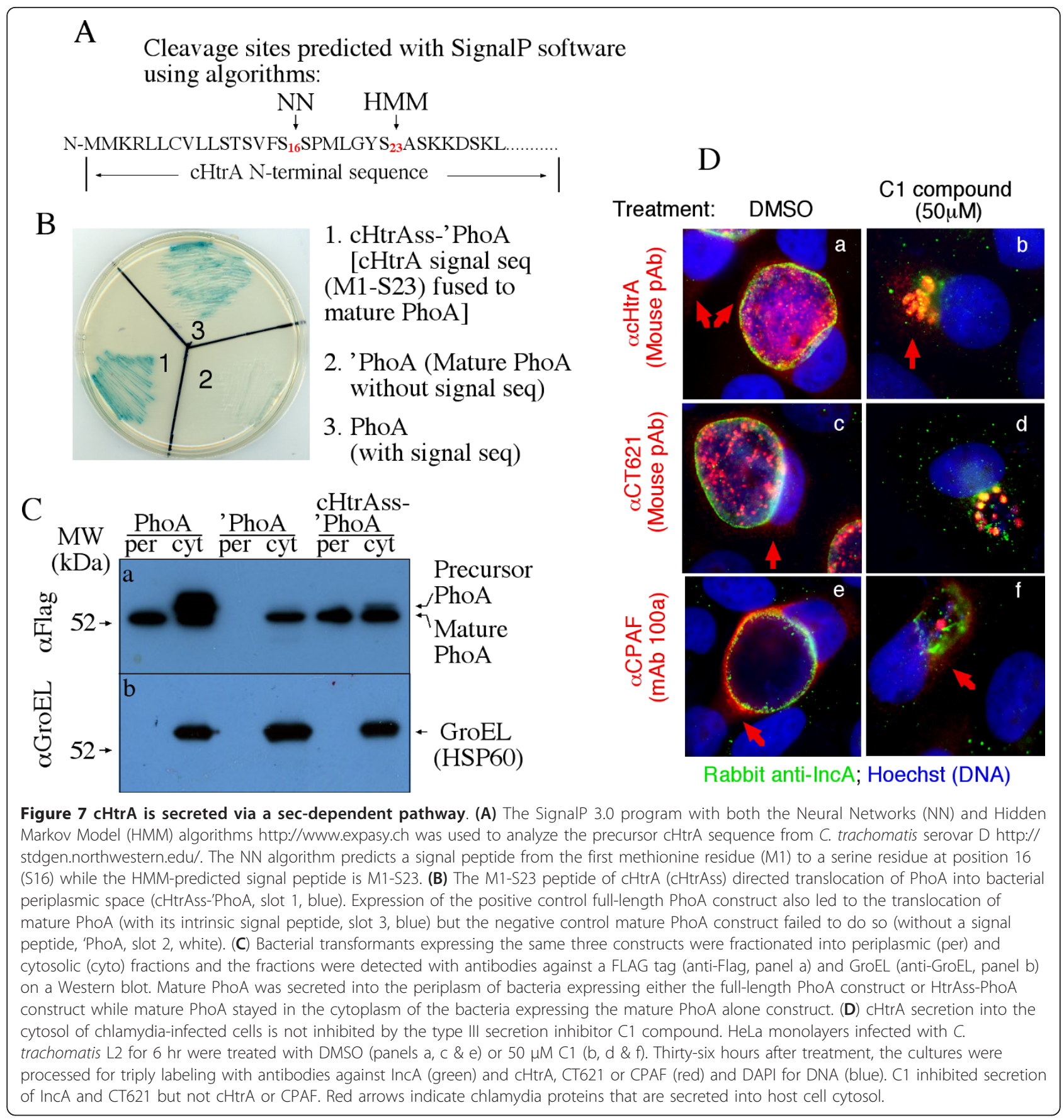

reference and under a confocal microscope. Second, the antibody labeling of cHtrA was removed by absorption with the cHtrA but not CPAF fusion proteins while the labeling of CPAF was removed by CPAF but not cHtrA fusion proteins, indicating that there was no cross-reactivity between anti-cHtrA and anti-CPAF antibodies. Third, in a Western blot with both HeLa alone and Chlamydiainfected whole cell lysates as antigens, the anti-cHtrA fusion protein antibodies detected a major protein band migrated at the molecular position expected for cHtrA, demonstrating that the anti-cHtrA antibodies specifically recognized the endogenous cHtrA without cross-reacting with any other cellular or chlamydial proteins. Fourth, the cytosolic cHtrA signals are likely due to active secretion but not passive leaking of cHtrA since various other abundant periplasmic proteins were not detected in the host cell cytosol. Finally, secretion of cHtrA into host cell cytosol was detected $24 \mathrm{~h}$ after infection while CPAF secretion occurred at $16 \mathrm{~h}$ after infection. Secretion of cHtrA was detected in most chlamydial species but not C. psittaci. 
These results together suggest that cHtrA secretion into host cell cytosol is a specific process and the secreted cHtrA may play an important role in chlamydial pathogenesis.

HtrA is a highly conserved serine protease present in the ER of eukaryotic and periplasmic space of bacterial cells. However, there has been no report on its secretion outside of eukaryotic or bacterial cells. Secretion of cHtrA out of chlamydial organisms may represent a unique feature Chlamydia has evolved during its interactions with host cells. A sec-dependent pathway may play an important role in exporting cHtrA into host cell cytosol since the $\mathrm{N}$-terminal leader peptide of cHtrA is functional and the secretion is not inhibitable by a type III secretion inhibitor. However, The sec-dependent pathway can only translocate cHtrA into the periplasmic region. It is still unknown how the periplasmic cHtrA passes through the outer membrane to enter the chlamydial inclusion lumen and further into host cell cytosol. The same challenge also applies to the secretion of CPAF. A sec-dependent pathway is necessary for CPAF secretion [62]. Similarly, how the periplasmic CPAF crosses the outer membrane remains unclear. Since CPAF was detected in granules in the lumen of inclusions during the early stage of chlamydial intracellular growth, an outer membrane vesicular budding model has been proposed for CPAF secretion into host cell cytosol [62], which may also be suitable for the secretion of cHtrA (Figure 8). Evidence for supporting this hypothesis comes from the observation that $\mathrm{cHtrA}$-laden granules/ vesicles that are free of chlamydial organisms were readily detected in the chlamydial inclusions. Although it remains to be determined how exactly cHtrA or CPAF is secreted out of the organisms and into host cell cytosol,

\section{A proposed model for C. trachomatis secretion of effectors into host cell cytosol}

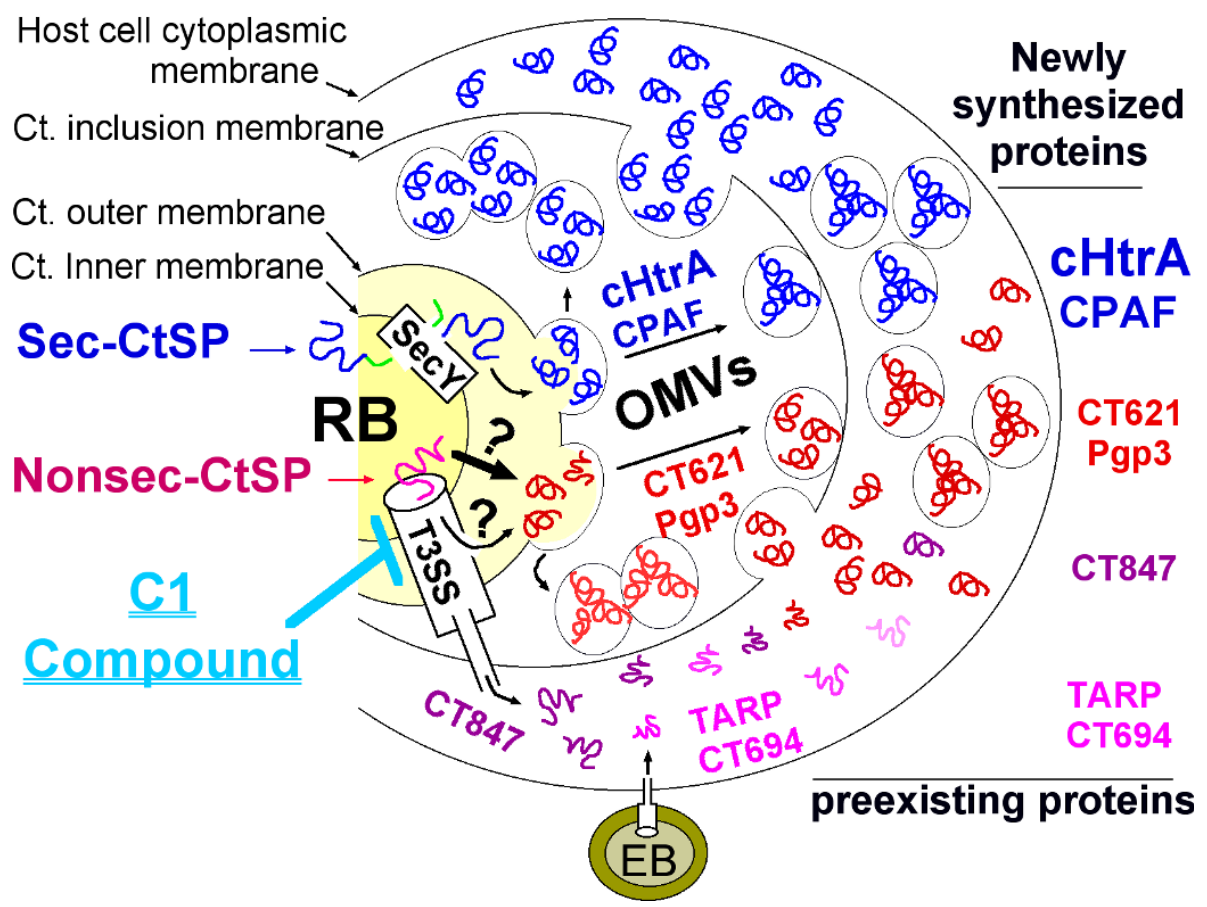

Figure 8 A proposed model for C. trachomatis secretion of effectors into host cell cytosol. When an infectious and metabolically inactive elementary body (EB) attaches to an epithelial cell, preexisting effectors such as TARP and CT694 can be injected into host cell cytosol via a single step type 3 secretion system (T3SS) for facilitating EB invasion. Once the internalized EB is differentiated into a non-infectious but metabolically active reticulate body (RB), newly synthesized chlamydial proteins can be secreted into host cell cytosol via either the single step T3SS (for example, secretion of CT847) or multi-step pathways. The C. trachomatis-secreted proteins (CtSPs) with an N-terminal signal sequence (termed Sec-CtSPs) such as CHtrA \& CPAF may be translocated into periplasm via a SecY-dependent pathway while those without any N-terminal signal sequences (Nonsec-CtSPs) may be translocated into the periplasmic space via a novel translocon or a leaking T3SS pathway. The periplasmically localized CtSPs may exit the chlamydial organisms via an outer membrane vesicle (OMV) budding mechanism. The CtSP-laden vesicles in the inclusion lumen can enter host cell cytosol via vesicle fusion with or passing through the inclusion membrane. That's why CT621 can be visualized in granules in the lumen of inclusion and its secretion can also be inhibited by C1, a small molecule inhibitor known to target bacterial T3SS. 
as more effector molecules are identified, more tools will be available for figuring out the secretion pathways Chlamydia has evolved for exporting virulence factors.

HtrA is a hexamer formed by two trimeric rings staggered on top of each other $[46,47]$. It possesses dual functions as both a chaperone and a protease [44]. Whether in eukaryotic ER or prokaryotic periplasmic space, HtrA can transmit the stress signals from unfold proteins into stress responses [48-51]. It appears that Chlamydia can respond to various stress signals by regulating the expression levels of cHtrA [45]. Although it is still unknown how the periplasmic cHtrA works, these previous observations can at least suggest that cHtrA is functional during chlamydial infection. Nevertheless, a more important question relevant to the current study is what roles cHtrA has after it is secreted into host cell cytosol and whether the secreted cHtrA contributes to chlamydial pathogenesis. Can the secreted cHtrA gain access to host cell ER to regulate host unfolded protein stress responses? What cellular proteins the secreted cHtrA molecules target during chlamydial infection in the presence or absence of stress stimulation. Efforts are underway to address these questions.

\section{Conclusions}

Secretion of chlamydial proteins into host cells is necessary for chlamydial organisms to establish and complete intracellular growth. Thus, identifying chlamydial proteins secreted into host cell cytoplasm has become a hot subject. Here, we have presented convincing evidence that the chlamydial periplasmic stress response serine protease cHtrA is secreted out of the chlamydial organisms into both chlamydial inclusion lumen and host cell cytosol. This secretion is specific since various other abundant chlamydial periplasmic proteins remained within the organisms. This novel finding suggests that the highly conserved cHtrA, in addition to its role in modifying chlamydial proteins in the periplasmic region, may also target host proteins, which is consistent with the overall concept that Chlamydia may use proteolysis as a powerful tool for manipulating host signaling pathways.

\section{Note added in proof}

During revision of the manuscript, Hoy et al published a report on Helicobacter pylori HtrA as a new secreted virulence factor that cleaves E-cadherin to disrupt intercellular adhesion. Hoy et al. 2010. EMBO reports. 11:798-804.

\section{Acknowledgements}

This work was supported in part by grants (to G. Zhong) from the US National Institutes of Health.

\section{Authors' contributions}

XW carried out most of the immunofluorescence and PhoA experiments; LL performed the confocal and Western blot assays as well as repeated some immunofluorescence assays; SG did the inhibitor experiment and carried out some immunofluorescence assays; RF participated in the

immunofluorescence experiments; DC participated in the design of the experiments and also provided technical guidance to XW. GZ conceived of the study, and participated in its design and coordination and drafted the manuscript. All authors read and approved the final manuscript.

Received: 31 October 2010 Accepted: 28 April 2011

Published: 28 April 2011

\section{References}

1. Wright HR, Turner A, Taylor HR: Trachoma. Lancet 2008, 371(9628):1945-1954.

2. Sherman KJ, Daling JR, Stergachis A, Weiss NS, Foy HM, Wang SP, Grayston JT: Sexually transmitted diseases and tubal pregnancy. Sex Transm Dis 1990, 17(3):115-121.

3. Peterman $T A$, Tian $L H$, Metcalf CA, Satterwhite CL, Malotte CK, DeAugustine N, Paul SM, Cross H, Rietmeijer CA, Douglas JM Jr: High incidence of new sexually transmitted infections in the year following a sexually transmitted infection: a case for rescreening. Ann Intern Med 2006, 145(8):564-572.

4. Mertz KJ, McQuillan GM, Levine WC, Candal DH, Bullard JC, Johnson RE, St Louis ME, Black CM: A pilot study of the prevalence of chlamydial infection in a national household survey. Sex Transm Dis 1998, 25(5):225-228.

5. Campbell LA, Kuo Cc: Chlamydia pneumoniae-an infectious risk factor for atherosclerosis? Nature reviews Microbiology 2004, 2(1):10.

6. Sharma J, Niu Y, Ge J, Pierce GN, Zhong G: Heat-inactivated C. pneumoniae organisms are not atherogenic. Mol Cell Biochem 2004, 260(1-2):147-152.

7. Hu H, Pierce GN, Zhong G: The atherogenic effects of chlamydia are dependent on serum cholesterol and specific to Chlamydia pneumoniae. J Clin Invest 1999, 103(5):747-753.

8. Read TD, Brunham RC, Shen C, Gill SR, Heidelberg JF, White O, Hickey EK, Peterson J, Utterback T, Berry K, et al: Genome sequences of Chlamydia trachomatis MoPn and Chlamydia pneumoniae AR39. Nucleic Acids Res 2000, 28(6):1397-1406.

9. Heddema ER, van Hannen EJ, Duim B, Vandenbroucke-Grauls CM, Pannekoek Y: Genotyping of Chlamydophila psittaci in human samples. Emerg Infect Dis 2006, 12(12):1989-1990.

10. Read TD, Myers GS, Brunham RC, Nelson WC, Paulsen IT, Heidelberg J, Holtzapple E, Khouri H, Federova NB, Carty HA, et al: Genome sequence of Chlamydophila caviae (Chlamydia psittaci GPIC): examining the role of niche-specific genes in the evolution of the Chlamydiaceae. Nucleic Acids Res 2003, 31(8):2134-2147.

11. Stephens RS, Kalman S, Lammel C, Fan J, Marathe R, Aravind L, Mitchell W, Olinger L, Tatusov RL, Zhao Q, et al: Genome sequence of an obligate intracellular pathogen of humans: Chlamydia trachomatis. Science 1998, 282(5389):754-759.

12. Hackstadt T, Fischer ER, Scidmore MA, Rockey DD, Heinzen RA: Origins and functions of the chlamydial inclusion. Trends Microbiol 1997, 5(7):288-293.

13. Su H, McClarty G, Dong F. Hatch GM, Pan ZK, Zhong G: Activation of Raf/ MEK/ERK/CPLA2 signaling pathway is essential for chlamydial acquisition of host glycerophospholipids. J Biol Chem 2004, 279(10):9409-9416.

14. Hackstadt T, Scidmore MA, Rockey DD: Lipid metabolism in Chlamydia trachomatis-infected cells: directed trafficking of Golgi-derived sphingolipids to the chlamydial inclusion. Proc Natl Acad Sci USA 1995, 92(11):4877-4881.

15. Cocchiaro JL, Kumar Y, Fischer ER, Hackstadt T, Valdivia RH: Cytoplasmic lipid droplets are translocated into the lumen of the Chlamydia trachomatis parasitophorous vacuole. Proc Natl Acad Sci USA 2008, 105(27):9379-9384.

16. McClarty G: Chlamydiae and the biochemistry of intracellular parasitism. Trends Microbiol 1994, 2(5):157-164.

17. Zhong G: Killing me softly: chlamydial use of proteolysis for evading host defenses. Trends Microbiol 2009, 17(10):467-474.

18. Rockey DD, Scidmore MA, Bannantine JP, Brown WJ: Proteins in the chlamydial inclusion membrane. Microbes Infect 2002, 4(3):333-340. 
19. Li Z, Chen C, Chen D, Wu Y, Zhong Y, Zhong G: Characterization of fifty putative inclusion membrane proteins encoded in the Chlamydia trachomatis genome. Infect Immun 2008, 76(6):2746-2757.

20. Valdivia RH: Chlamydia effector proteins and new insights into chlamydial cellular microbiology. Curr Opin Microbiol 2008, 11(1):53-59.

21. Fields KA, Mead DJ, Dooley CA, Hackstadt T: Chlamydia trachomatis type III secretion: evidence for a functional apparatus during early-cycle development. Mol Microbiol 2003, 48(3):671-683.

22. Subtil A, Delevoye C, Balana ME, Tastevin L, Perrinet S, Dautry-Varsat A: A directed screen for chlamydial proteins secreted by a type III mechanism identifies a translocated protein and numerous other new candidates. Mol Microbiol 2005, 56(6):1636-1647.

23. Hower S, Wolf K, Fields KA: Evidence that CT694 is a novel Chlamydia trachomatis T3S substrate capable of functioning during invasion or early cycle development. Mol Microbiol 2009, 72(6):1423-1437.

24. Chellas-Gery B, Linton CN, Fields KA: Human GCIP interacts with CT847, a novel Chlamydia trachomatis type III secretion substrate, and is degraded in a tissue-culture infection model. Cell Microbiol 2007, 9(10):2417-2430.

25. Clifton DR, Fields KA, Grieshaber SS, Dooley CA, Fischer ER, Mead DJ, Carabeo RA, Hackstadt T: A chlamydial type III translocated protein is tyrosine-phosphorylated at the site of entry and associated with recruitment of actin. Proc Natl Acad Sci USA 2004, 101(27):10166-10171.

26. Zhong G, Fan P, Ji H, Dong F, Huang Y: Identification of a chlamydial protease-like activity factor responsible for the degradation of host transcription factors. J Exp Med 2001, 193(8):935-942.

27. Dong F, Flores R, Chen D, Luo J, Zhong Y, Wu Z, Zhong G: Localization of the hypothetical protein Cpn0797 in the cytoplasm of Chlamydia pneumoniae-infected host cells. Infect Immun 2006, 74(11):6479-6486.

28. Vandahl BB, Stensballe A, Roepstorff P, Christiansen G, Birkelund S: Secretion of Cpn0796 from Chlamydia pneumoniae into the host cell cytoplasm by an autotransporter mechanism. Cell Microbiol 2005, 7(6):825-836

29. Li Z, Chen D, Zhong Y, Wang S, Zhong G: The chlamydial plasmidencoded protein pgp3 is secreted into the cytosol of Chlamydiainfected cells. Infect Immun 2008, 76(8):3415-3428.

30. Hobolt-Pedersen AS, Christiansen G, Timmerman E, Gevaert K, Birkelund S: Identification of Chlamydia trachomatis CT621, a protein delivered through the type III secretion system to the host cell cytoplasm and nucleus. FEMS Immunol Med Microbiol 2009, 57(1):46-58.

31. Misaghi S, Balsara ZR, Catic A, Spooner E, Ploegh HL, Starnbach MN: Chlamydia trachomatis-derived deubiquitinating enzymes in mammalian cells during infection. Mol Microbiol 2006, 61(1):142-150.

32. Huang Z, Feng $Y$, Chen D, Wu X, Huang S, Wang X, Xiao X, Li W, Huang N, Gu L, et al: Structural Basis for Activation and Inhibition of the Secreted Chlamydia Protease CPAF. Cell Host Microbe 2008, 4(6):529-542.

33. Chen D, Chai J, Hart PJ, Zhong G: Identifying catalytic residues in CPAF, a Chlamydia-secreted protease. Arch Biochem Biophys 2009, 485(1):16-23.

34. Dong F, Su H, Huang Y, Zhong Y, Zhong G: Cleavage of host keratin 8 by a Chlamydia-secreted protease. Infect Immun 2004, 72(7):3863-3868.

35. Kumar Y, Valdivia RH: Actin and intermediate filaments stabilize the Chlamydia trachomatis vacuole by forming dynamic structural scaffolds. Cell Host Microbe 2008, 4(2):159-169.

36. Scidmore M: Chlamydia weave a protective cloak spun of actin and intermediate filaments. Cell Host Microbe 2008, 4(2):93-95.

37. Zhong G, Fan T, Liu L: Chlamydia inhibits interferon gammainducible major histocompatibility complex class II expression by degradation of upstream stimulatory factor 1. J Exp Med 1999, 189(12):1931-1938.

38. Zhong G, Liu L, Fan T, Fan P, Ji H: Degradation of transcription factor RFX5 during the inhibition of both constitutive and interferon gammainducible major histocompatibility complex class I expression in chlamydia-infected cells. J Exp Med 2000, 191(9):1525-1534.

39. Pirbhai M, Dong F, Zhong Y, Pan KZ, Zhong G: The secreted protease factor CPAF is responsible for degrading pro-apoptotic $\mathrm{BH} 3$-only proteins in Chlamydia trachomatis-infected cells. J Biol Chem 2006, 281(42):31495-31501

40. Fan T, Lu H, Hu H, Shi L, McClarty GA, Nance DM, Greenberg AH, Zhong G: Inhibition of apoptosis in chlamydia-infected cells: blockade of mitochondrial cytochrome $\mathrm{c}$ release and caspase activation. J Exp Med 1998, 187(4):487-496
41. Lad SP, Li J, da Silva Correia J, Pan Q, Gadwal S, Ulevitch RJ, Li E: Cleavage of p65/RelA of the NF-kappaB pathway by Chlamydia. Proc Natl Acad Sci USA 2007, 104(8):2933-2938.

42. Lad SP, Yang G, Scott DA, Wang G, Nair P, Mathison J, Reddy VS, Li E: Chlamydial CT441 is a PDZ domain-containing tail-specific protease that interferes with the NF-kappaB pathway of immune response. J Bacteriol 2007, 189(18):6619-6625.

43. Chen D, Lei L, Flores R, Huang Z, Wu Z, Chai J, Zhong G: Autoprocessing and self-activation of the secreted protease CPAF in Chlamydia-infected cells. Microb Pathog 2010.

44. Huston WM, Swedberg JE, Harris JM, Walsh TP, Mathews SA, Timms P: The temperature activated HtrA protease from pathogen Chlamydia trachomatis acts as both a chaperone and protease at 37 degrees $C$. FEBS Lett 2007, 581(18):3382-3386.

45. Huston WM, Theodoropoulos C, Mathews SA, Timms P: Chlamydia trachomatis responds to heat shock, penicillin induced persistence, and IFN-gamma persistence by altering levels of the extracytoplasmic stress response protease HtrA. BMC Microbiol 2008, 8:190.

46. Krojer T, Garrido-Franco M, Huber R, Ehrmann M, Clausen T: Crystal structure of DegP $(\mathrm{Htr} A)$ reveals a new protease-chaperone machine. Nature 2002, 416(6879):455-459.

47. Krojer T, Sawa J, Huber R, Clausen T: HtrA proteases have a conserved activation mechanism that can be triggered by distinct molecular cues. Nat Struct Mol Biol 2010, 17(7):844-852.

48. Ye J, Rawson RB, Komuro R, Chen X, Dave UP, Prywes R, Brown MS, Goldstein JL: ER stress induces cleavage of membrane-bound ATF6 by the same proteases that process SREBPs. Mol Cell 2000, 6(6):1355-1364.

49. Brown MS, Goldstein JL: A proteolytic pathway that controls the cholesterol content of membranes, cells, and blood. Proc Natl Acad Sci USA 1999, 96(20):11041-11048.

50. Walsh NP, Alba BM, Bose B, Gross CA, Sauer RT: OMP peptide signals initiate the envelope-stress response by activating DegS protease via relief of inhibition mediated by its PDZ domain. Cell 2003, 113(1):61-71.

51. Missiakas D, Mayer MP, Lemaire M, Georgopoulos C, Raina S: Modulation of the Escherichia coli sigmaE (RpoE) heat-shock transcription-factor activity by the RseA, RseB and RseC proteins. Mol Microbiol 1997, 24(2):355-371.

52. Wolf K, Betts HJ, Chellas-Gery B, Hower S, Linton CN, Fields KA: Treatment of Chlamydia trachomatis with a small molecule inhibitor of the Yersinia type III secretion system disrupts progression of the chlamydial developmental cycle. Mol Microbiol 2006, 61(6):1543-1555.

53. Sharma J, Zhong Y, Dong F, Piper JM, Wang G, Zhong G: Profiling of human antibody responses to Chlamydia trachomatis urogenital tract infection using microplates arrayed with 156 chlamydial fusion proteins. Infect Immun 2006, 74(3):1490-1499.

54. Sharma J, Bosnic AM, Piper JM, Zhong G: Human antibody responses to a Chlamydia-secreted protease factor. Infect Immun 2004, 72(12):7164-7171.

55. Zhong G, Reis e Sousa C, Germain RN: Production, specificity, and functionality of monoclonal antibodies to specific peptide-major histocompatibility complex class II complexes formed by processing of exogenous protein. Proc Natl Acad Sci USA 1997, 94(25):13856-13861.

56. Hackstadt T, Scidmore-Carlson MA, Shaw El, Fischer ER: The Chlamydia trachomatis IncA protein is required for homotypic vesicle fusion. Cell Microbiol 1999, 1(2):119-130.

57. Swanson KA, Taylor LD, Frank SD, Sturdevant GL, Fischer ER, Carlson JH, Whitmire WM, Caldwell HD: Chlamydia trachomatis polymorphic membrane protein $D$ is an oligomeric autotransporter with a higherorder structure. Infect Immun 2009, 77(1):508-516.

58. Kumar Y, Cocchiaro J, Valdivia RH: The obligate intracellular pathogen Chlamydia trachomatis targets host lipid droplets. Curr Biol 2006, 16(16):1646-1651.

59. Miller JD, Sal MS, Schell M, Whittimore JD, Raulston JE: Chlamydia trachomatis $\mathrm{Ytg} A$ is an iron-binding periplasmic protein induced by iron restriction. Microbiology 2009, 155(Pt 9):2884-2894.

60. Raulston JE, Miller JD, Davis $\mathrm{CH}$, Schell M, Baldwin A, Ferguson $\mathrm{K}$, Lane $\mathrm{H}$ : Identification of an iron-responsive protein that is antigenic in patients with Chlamydia trachomatis genital infections. FEMS Immunol Med Microbiol 2007, 51(3):569-576.

61. Jomaa A, Iwanczyk J, Tran J, Ortega J: Characterization of the autocleavage process of the Escherichia coli HtrA protein: implications for its physiological role. J Bacteriol 2009, 191(6):1924-1932. 
62. Chen D, Lei L, Lu C, Flores R, DeLisa D, Roberts TC, Romesberg FE, Zhong G: Secretion of the Chlamydial Virulence Factor CPAF Requires Sec-Dependent Pathway. Microbiology 2010, 156:3031.

doi:10.1186/1471-2180-11-87

Cite this article as: Wu et al:: The chlamydial periplasmic stress

response serine protease $\mathrm{CH}$ trA is secreted into host cell cytosol. BMC

Microbiology 2011 11:87.

Submit your next manuscript to BioMed Central and take full advantage of:

- Convenient online submission

- Thorough peer review

- No space constraints or color figure charges

- Immediate publication on acceptance

- Inclusion in PubMed, CAS, Scopus and Google Scholar

- Research which is freely available for redistribution

Submit your manuscript at 